\title{
Acúmulo de massa seca em cultivares de Brachiaria brizantha submetida a intensidades de desfolhação
}

\section{Herbage accumulation in Brachiaria brizantha cultivars submitted to defoliation intensities}

\author{
João Guilherme de Góis Fontes ${ }^{1 *}$; Jailson Lara Fagundes ${ }^{2}$; Alfredo Acosta Backes ${ }^{2}$; \\ Leandro Teixeira Barbosa²; Elder Sânzio Aguiar Cerqueira3 ${ }^{3}$ Laerte Marques da Silva ${ }^{4}$; \\ Juciléia Aparecida da Silva Morais ${ }^{2}$; Jodnes Sobreira Vieira ${ }^{2}$
}

\section{Resumo}

O experimento foi realizado com o objetivo de avaliar o efeito de diferentes intensidades de desfolhação no acúmulo de matéria seca, composição morfológica e resíduo de forragem de cultivares de Brachiaria brizantha. Os tratamentos consistiram em três cultivares de Brachiaria brizantha (Marandú, Xaraés e MG4) e quatro intensidades de desfolhação $(10,20,30$ e $40 \mathrm{~cm})$ durante o período de agosto de 2010 a julho de 2011. O delineamento experimental foi o de blocos casualizados com quatro repetições em fatorial $3 \times 4$. As cultivares apresentaram comportamento significativo sob as diferentes intensidades de desfolhação, acúmulo de massa seca total e de folha, percentagem de material morto e altura do dossel. Quando submetido às diferentes intensidades de desfolhação não foi constatado efeito significativo para o acúmulo de colmo, percentagem de colmo, densidade da forragem e relação folha:colmo. As cultivares Marandú e Xaraés apresentaram maior acúmulo de folha, maior altura de dossel e relação folha:colmo do que o MG4. A participação de material verde na matéria seca e o resíduo de matéria seca é altamente influenciável pela intensidade de desfolha.

Palavras-chave: Forrageira tropical, pastagem, produtividade, relação folha: colmo

\begin{abstract}
This experiment was conducted to evaluate the effect of different grazing intensities on the accumulation of dry matter and morphological composition of Brachiaria brizantha cultivars. The treatment consisted of three cultivars of Brachiaria brizantha (Marandú, Xaraés and MG4) and four levels of defoliation (10, 20, 30 and $40 \mathrm{~cm}$ ) in the period from August 2010 to July 2011. The experimental design was a randomized blocks with four replications in a $3 \times 4$ factorial arrangement. Cultivars showed significant behavior under different defoliation intensities as regards total dry matter and leaf accumulations, and percentage of dead material and canopy height. When subjected to different defoliation intensities, no significant effect was verified on stem accumulation, percentage of stems, forage density or leaf:stem ratio. Cultivars Marandú and Xaraés showed greater leaf accumulation, canopy height and higher leaf:stem ratio than cultivar MG4. The participation of green material in the dry matter and dry matter residue are highly influenced by defoliation intensity.
\end{abstract}

Key words: Tropical forage, pasture, productivity, leaf: stem ratio

\footnotetext{
${ }^{1}$ Discente do Curso de Mestrado em Zootecnia, Universidade Federal de Sergipe, UFS, São Cristóvão, SE. E-mail: jguifontes@ hotmail.com

${ }^{2}$ Profs. do Dept ${ }^{\circ}$ de Zootecnia, UFS, São Cristóvão, SE. E-mail: ratinhojlf@yahoo.com.br; alfredoaab_67@yahoo.com.br; leandro35441@yahoo.com.br; juci_morais@yahoo.com.br; jodsvi@gmail.com

${ }^{3}$ Prof. do Dept ${ }^{\circ}$ de Engenharia Agrícola, UFS, São Cristóvão, SE. E-mail: eldersanzio@gmail.com

${ }^{4}$ Prof. do Dept ${ }^{\circ}$ de Engenharia Agronômica, UFS, São Cristóvão, SE. E-mail: laertemarquesilva@hotmail.com

* Autor para correspondência
} 


\section{Introdução}

A produção de ruminantes no Brasil é de grande importância econômica apresentando-se como atividade de baixo custo quando a alimentação é baseada no uso de pastagens, entretanto, ainda é necessário que ocorra melhoria quantitativa e qualitativa nas pastagens para elevar os índices de produtividade animal a pasto (SILVA et al., 2008). A disponibilidade de gramíneas forrageiras com elevado potencial de produção de massa, é um fato que vem contribuindo para o aumento da capacidade de suporte das pastagens. Dentre as gramíneas forrageiras utilizadas na alimentação animal, as cultivares da espécie Brachiaria brizantha têm se destacado por apresentarem elevada produção de massa seca, bom valor nutritivo, boa aceitabilidade e alta capacidade de suporte animal, estando bastante disseminadas no Brasil, e recomendadas para diversos sistemas de produção de ruminantes (TEIXEIRA et al., 2003).

Existe uma variação grande de cultivares de Brachiaria, sendo que algumas dessas apresentam diferenças morfológicas e estruturais, mesmo apresentando bom valor nutritivo e boa relação folha/haste. Segundo Fagundes et al. (2005), isto justifica, a necessidade de conhecimentos mais detalhados sobre as plantas forrageiras, considerando-se que mudanças morfológicas e estruturais no pasto ocorrem ao longo do tempo. A utilização de espécies e ou cultivares de Brachiaria em sistemas de produção de ruminantes em pastejo foi proporcionada pelo conjunto de características desejáveis dessas forrageiras, que vem a ocorrer devido a sua adaptação a variadas condições de solo e clima (FAGUNDES et al., 2006).

A Brachiaria brizantha Stapf. cv. Marandú apresenta-se como uma opção para os pecuaristas pelas suas características agronômicas, e tem permitido ocupação de extensas áreas no Brasil Central. A Brachiaria brizantha Hochst Stapf cv. MG-4, originária da Colômbia, é tolerante a regiões com baixos índices pluviométricos $(>800 \mathrm{~mm})$, devido ao seu sistema radicular profundo e, ainda, solos com menor fertilidade, já a cultivar Xaraés, tem como uma das características mais importante, a boa produção de massa seca, resistência às secas, rápida rebrota após o pastejo, e tolerância a solos mal drenados (VALLE et al., 2003).

Os estudos de pastagem no Brasil, tem caráter regional, ocorrendo práticas de manejo extremamente generalistas, e apresentando grande inconsistência de informações, necessitando de melhores conhecimentos dessas gramíneas e as respostas aos diferentes manejos. Casagrande et al. (2010), relataram que a dinâmica dos processos de crescimento e desenvolvimento das plantas e suas mudanças morfofisiológicas são fatores que interferem na produção animal, sobretudo na intensidade de pastejo. Aredução do consumo animal e as perdas de alimento em uma pastagem, podem estar diretamente relacionadas ao manejo empregado a ela, mudando características importantes nas fases de crescimento, desenvolvimento e senescência. Logo o regime de desfolhação determina a área foliar remanescente pós-pastejo e a rebrotação é condicionada pela emissão de nova área foliar a partir desta área foliar remanescente. Contudo, a intensidade de desfolhação em sistemas de pastejo e de corte não estão bem definidas para todas as plantas forrageiras. Para tanto, realizou-se este trabalho objetivando-se avaliar as características produtivas, estruturais e morfogênicas do dossel de Brachiaria brizantha, cv. Marandú, Xaraés e MG4, em diferentes intensidades de desfolhação.

\section{Material e Métodos}

O experimento foi conduzido de agosto de 2010 a julho de 2011, em pastagens de Brachiaria brizantha estabelecidas no ano de 2009, na área do Campus Rural da Universidade Federal de Sergipe, localizado no município de São Cristóvão-SE, com coordenadas geográficas $10^{\circ} 55^{\prime} 20^{\prime \prime}$ de latitude Sul e $37^{\circ} 12^{\prime} 00^{\prime}$ de longitude Oeste, e altitude de 20 metros ao nível do mar. 
O delineamento experimental utilizado foi em blocos casualizados em esquema fatorial $3 \times 4$, ou seja, três cultivares de Brachiaria brizantha (Urochoa Brizantha) (Marandú, MG4 e Xaraés), e quatro intensidades de desfolhação $(10,20,30$ e $40 \mathrm{~cm}$ ), com quatro repetições. As alturas foram medidas a partir do solo com régua graduada, sendo colhidas quando estas atingiam $60 \mathrm{~cm}$ acima dos valores de intensidade pré-estabelecido (10, 20, 30 e $40 \mathrm{~cm}$ ), ou seja, quando as plantas atingiam as alturas de 70, 80, 90 e $100 \mathrm{~cm}$, sendo realizado 5 cortes durante o período experimental. As unidades experimentais constituíram-se de quarenta e oito parcelas de 4,0 $\mathrm{m}^{2}(2,0 \times 2,0 \mathrm{~m})$, com área útil de coleta de $1,0 \mathrm{~m}^{2}$ na parte central da parcela, e o restante eliminado como bordadura.

O experimento foi instalado em solo classificado como Argissolo Vermelho Amarelo, distrófico típico, textura arenosa/média e topografia ondulada (EMBRAPA, 1999) e com as seguintes características: $\mathrm{pH}\left(\mathrm{CaCl}_{2}\right)=4,8 ; \mathrm{MO}\left(\mathrm{g} \mathrm{DM}^{-3}\right)=$ 11,2; $\mathrm{P}\left(\mathrm{mg} \mathrm{dm}^{-3}\right)=16,0 ; \mathrm{K}\left(\mathrm{cmolc} \mathrm{dm}^{-3}\right)=0,09 ; \mathrm{Ca}$ $\left(\mathrm{cmolcdm}^{-3}\right)=0,75 ; \mathrm{Mg}\left(\mathrm{cmolc} \mathrm{dm}^{-3}\right)=0,33 ; \mathrm{H}+\mathrm{Al}$ $\left(\mathrm{cmolcdm}^{-3}\right)=2,65 ; \mathrm{SB}\left(\mathrm{cmolc} \mathrm{dm}^{-3}\right)=1,75 \mathrm{e} \mathrm{V}(\%)$ $=39,9$.

Os resultados da análise de solo foram utilizados para a recomendação de adubação e calagem, conforme descrito por Lima e Vilela (2005). A calagem foi realizada de forma a elevar a saturação de bases a $70 \%$, e a adubação de base foi $120 \mathrm{~kg} / \mathrm{ha}$ de P2O5, na forma de superfosfato triplo, $80 \mathrm{~kg} / \mathrm{ha}$ $\mathrm{K}_{2} \mathrm{O}$ aplicado após o corte de uniformização e $100 \mathrm{~kg} /$ ha de nitrogênio, na forma de ureia, como adubação de cobertura distribuídos em três aplicações (5 de agosto, 17 de fevereiro e 2 de maio).

Inicialmente foi realizado um corte de uniformização em todas as parcelas ao nível do solo e semanalmente foram realizadas medidas de altura do dossel forrageiro para acompanhar o desenvolvimento das plantas. Quando mais de 75 $\%$ das parcelas experimentais atingiam a altura de corte pré-definidas foi colhido o material da parcela e em seguida, realizado as avaliações da produção de forragem, composição morfológica do pasto, massa de forragem, altura das plantas, relação folha:colmo e densidade volumétrica de forragem.

A avaliação do acúmulo de forragem foi estimado pelo método agronômico das diferenças conforme a equação I (DAVIES, 1993). Antes de se proceder o corte da forragem em uma área de solo de $1 \mathrm{~m}^{2}$, foi realizado a mensuração da altura média do pasto por meio de régua graduada.

$$
\text { Equação I } \quad \mathrm{AF}=\mathrm{MF}_{\text {final }}-\mathrm{MF}_{\text {inicio }}
$$

sendo:

$\mathrm{AF}=$ Acúmulo de Forragem;

$\mathrm{MF}_{\text {final }}=$ Massa de Forragem no dia final da avaliação ou corte;

$\mathrm{MF}_{\text {inicio }}=$ Massa de Forragem no dia do início da avaliação.

Após o corte da forragem nas parcelas experimentais, as mesmas foram acondicionadas em sacos de polietileno, pesadas e repicadas duas sub-amostras de forragem. Uma sub-amostra foi levada para secagem em estufa a $65^{\circ} \mathrm{C}$ até massa constante, para calculo da massa seca acumulada. A segunda sub-amostra foi utilizada para avaliação da composição morfológica da forragem, na qual o material foi fracionado em folhas (lâminas verdes), colmos (colmos e bainhas foliares) e material morto das cultivares de interesse. Após a separação, todos os componentes foram levados para secagem em estufa a $65^{\circ} \mathrm{C}$ até massa constante. Após secagem, essa amostra fracionada foi pesada e, por intermédio das relações entre massa seca e massa verde da sub-amostra, sendo calculado a matéria seca de cada componente da forragem colhida na área de amostragem.

A composição morfológica do material avaliado, foi obtido por meio da média de todos os cortes das parcelas e o acúmulo de matéria seca por meio do somatório da MS de todos os cortes. De posse dos dados de massa de forragem verde (colmo + 
folhas vivas) e da altura do dossel, foi calculada a densidade volumétrica de forragem verde $(\mathrm{kg} /$ ha.cm de MS).

Foi computado diariamente a média de precipitação pluvial ocorrida durante o experimento, o qual está representado por médias mensais na
Tabela 1 (SEMARH, 2012).

Os dados foram submetidos à analise estatística segundo o procedimento PROC GLM do pacote estatístico SAS (2002). Para a comparação de médias as variáveis foram submetidas ao teste de Tukey $(\mathrm{P}<0,05)$.

Tabela 1. Médias mensais de precipitação pluvial total durante o período de agosto de 2010 a julho de 2011.

\begin{tabular}{cccc}
\hline Mês / Ano & Precipitação $(\mathrm{mm})$ & Temperatura (média) & Umidade (\%) \\
\hline Agosto / 2010 & 124,8 & 23,5 & 85 \\
Setembro / 2010 & 101,0 & 24,0 & 80 \\
Outubro / 2010 & 11,5 & 25,6 & 86 \\
Novembro / 2010 & 10,5 & 26,8 & 81 \\
Dezembro / 2010 & 11,3 & 27,1 & 79 \\
Janeiro / 2011 & 146,9 & 29,0 & 75 \\
Fevereiro / 2011 & 106,5 & 28,3 & 73 \\
Março / 2011 & 60,7 & 29,8 & 85 \\
Abril / 2011 & 273,0 & 26,1 & 89 \\
Maio / 2011 & 256,0 & 25,0 & 91 \\
Junho / 2011 & 103,6 & 23,8 & 92 \\
Julho / 2011 & 160,9 & 23,3 & 79 \\
\hline Total & 1366,7 & 26,0 (média) & 83 (média) \\
\hline
\end{tabular}

Fonte: SEMARH (2012).

\section{Resultados e Discussão}

Foi constatado efeito significativo da intensidade de desfolhação $(\mathrm{P}<0,05)$ sobre acúmulo de colmo, porcentagem de colmo, densidade volumétrica de forragem e relação folha:colmo (Tabela 2).

$\mathrm{O}$ acúmulo de forragem total não apresentou diferença significativa $(\mathrm{P}>0,05)$ nas diferentes intensidades de desfolhação. Resultado similar foi observado por Mari (2003) que trabalhou com intervalos de dias fixos de colheita variando entre 15 e 90 dias, e relatou amplitude produtiva de 20,2 a 28,2 t ha/ano. Silva et al. (2011) e Molan (2004), trabalhando com o capim Marandú com diferentes alturas de corte, observaram que à medida que se aumentava a altura do corte, reduzia o teor de matéria seca. No presente trabalho o crescimento foi independente da intensidade de desfolha, corroborando com os resultados obtidos por Humphreys (1966), ao trabalhar com Panicum maximum. $\mathrm{O}$ esperado seria produções mais elevadas em regimes de desfolha mais leniente, menos frequentes e intensos, no entanto, pode ter ocorrido maior eficiência foliar (folhas desenvolvidas em ambientes com maior disponibilidade de luz) e o corte de uniformização pode ter influenciado as reservas das raízes e o desenvolvimento de perfilho. 
Tabela 2. Acúmulo de matéria seca ( $\mathrm{kg} / \mathrm{ha})$, composição morfofisiológicas (\%), relação folha:colmo, densidade volumétrica de forragem $(\mathrm{kg} / \mathrm{cm}$.ha) e altura do dossel forrageiro das cultivares de Brachiaria brizantha submetido a intensidades de desfolhação.

\begin{tabular}{|c|c|c|c|c|c|}
\hline \multirow{2}{*}{ Variáveis } & \multicolumn{4}{|c|}{ Intensidade de desfolhação } & \multirow{2}{*}{ CV $(\%)$} \\
\hline & $10 \mathrm{~cm}$ & $20 \mathrm{~cm}$ & $30 \mathrm{~cm}$ & $40 \mathrm{~cm}$ & \\
\hline & \multicolumn{4}{|c|}{ 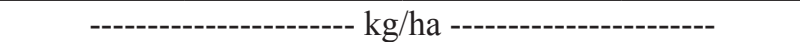 } & \\
\hline Acúmulo de forragem total & 28.600 & 29.001 & 23.235 & 22.429 & 25,9 \\
\hline Acúmulo de Colmo & $11.377 \mathrm{~A}$ & $10.630 \mathrm{AB}$ & $7.127 \mathrm{BC}$ & $6.904 \mathrm{C}$ & 36,2 \\
\hline Acúmulo de Folha & 12.877 & 13.791 & 11.634 & 11.633 & 21,6 \\
\hline Percentagem de Material Morto & 15,22 & 16,53 & 17,36 & 15,70 & 22,3 \\
\hline Percentagem de Colmo & $37,85 \mathrm{~A}$ & $34,53 \mathrm{~A}$ & $29,72 \mathrm{~B}$ & $28,78 \mathrm{~B}$ & 12,6 \\
\hline \multirow[t]{2}{*}{ Percentagem de Folha } & 53,07 & 51,06 & 47,08 & 44,48 & 14,8 \\
\hline & & ----- kg & ha - & ----- & \\
\hline Densidade de Forragem & $85,08 \mathrm{~A}$ & $82,17 \mathrm{~A}$ & $64,50 \mathrm{~B}$ & $59,25 \mathrm{~B}$ & 19,4 \\
\hline Altura do Dossel forrageiro & 86,42 & 88,50 & 90,25 & 93,33 & 12,5 \\
\hline Relação folha:colmo & $1,21 \mathrm{~B}$ & $1,39 \mathrm{~B}$ & $1,67 \mathrm{~A}$ & $1,72 \mathrm{~A}$ & 16,9 \\
\hline
\end{tabular}

Médias seguidas por pelo menos uma mesma letra são iguais $(\mathrm{P}>0,05)$.

Fonte: Elaboração dos autores.

Verificou-se que à medida que diminuía-se a intensidade de desfolhação $(30$ e $40 \mathrm{~cm}$ ) ocorreu redução no acúmulo de colmo. Este fato pode ser explicado pela localização dos colmos na parte inferior do dossel forrageiro, portanto, quando se diminui a intensidade de desfolhação removem-se maior quantidade de folhas e menor quantidade de colmo.

A percentagem de material morto não apresentou diferença significativa entre as intensidades de desfolha $(\mathrm{P}>0,05)$, no entanto, apresentou níveis elevados, como constatado por Bircham e Hodgson (1983), que ao descreverem a curva de crescimento da planta forrageira e o fluxo de tecidos, relataram que inicialmente há um crescimento de colmo e folha, e à medida que o dossel atinge a saturação de interceptação luminosa, a produção se estabiliza, e ocorre tendência do crescimento liquido ser reduzido devido ao aumento da senescência.

Ao analisar a porcentagem de colmo no dossel notou-se que os maiores valores percentuais de colmo ocorreram nas maiores intensidades de desfolhação. Este resultado é refletido na densidade volumétrica de forragem e na relação folha:colmo, ou seja nas maiores alturas ocorreu uma menor densidade volumétrica e uma maior relação folha:colmo. Resultados similares foram relatados por Marcelino et al. (2006) e Rodrigues (2004), que constataram em capim Marandú e Xaraés, um aumento da massa de colmo em decorrência do aumento da intensidade de desfolhação.

A percentagem de colmo teve uma maior contribuição quando se colheu as parcelas na intensidade de 10 e $20 \mathrm{~cm}$, o que pode ser explicado pela posição dos colmos estarem localizados na parte mais próxima ao solo, portanto quando o pasto é colhido a 10 e $20 \mathrm{~cm}$ grande quantidade de colmo é removido. Sarmento (2007), trabalhando com diferentes alturas de resíduo, em animais em pastejo, observou dificuldade em deixar o resíduo a $10 \mathrm{~cm}$ do solo, em decorrência do elevado percentual de colmo. 
O acúmulo de folha não sofreu influência das diferentes intensidades de desfolha. Uma possível explicação é que durante a fase de crescimento ocorrem mudanças morfológicas no perfil do dossel gerando maior acúmulo de folha, que nas diferentes alturas pode ter saturado a fase de crescimento desde a maior até a menor intensidade de desfolha (10 a $40 \mathrm{~cm}$ ) e com isso limitado o acúmulo de folha (FAGUNDES et al., 2006).

É possível que ocorra maior índice de área foliar à medida que o dossel fica mais alto, aumentando a interceptação luminosa, acarretando acentuada competição por luz e refletindo em maior alongamento de colmo e morte das folhas mais velhas, o que pode causar uma maior rejeição animal. A presença de colmo pode reduzir a eficiência do sistema, limitando a capacidade de colheita pelo animal e reduzindo a qualidade do alimento, provocando rejeição deste componente pelo animal (BALSALOBRE et al., 2003; CASAGRANDE et al., 2010).

À medida que diminuiu a intensidade de desfolhação ocorreu redução na densidade de forragem, o que pode prejudicar o consumo animal em decorrência da taxa de bocado. Estes resultados corroboram com os encontrados por Molan (2004), que também observou redução na densidade de forragem à medida que aumentou a altura do dossel.

A relação folha:colmo sofreu influência da intensidade de corte sendo que nas menores intensidades foram observados os maiores valores da relação folha:colmo. Flores et al. (2008), trabalhando com diferentes cultivares de Brachiaria brizantha, observaram resultados de folha:colmo inferiores aos encontrados neste trabalho. Segundo Castagnara et al. (2011), a relação folha:colmo é de grande importância para a nutrição animal, estando associado à facilidade de alimentação das partes mais nutritiva da planta forrageira. Os valores nas diferentes alturas de colheita, foram superiores ao nível considerado crítico (1:1), relatado por Pinto et al., (1994). Pode se inferir que nas menores intensidades de desfolhação, há forragem de melhor qualidade, haja visto que os maiores valores da relação folha:colmo e menores valores da quantidade de colmo, são encontrado nos cortes ou pastejos mais lenientes.

Foi constatado efeito das cultivares de Brachiaria $(\mathrm{P}<0,05)$ no acúmulo de folha, porcentagem de material morto e colmo, densidade volumétrica de forragem, relação folha:colmo e altura do dossel (Tabela 3).

O acúmulo de forragem total e de colmo, não apresentaram diferença entre os cultivares, diferente do encontrado por Pedreira, Pedreira e Silva (2007). O acúmulo de massa seca no presente trabalho, apresentaram valores superiores aos relatados por Carard, Neres e Tonello (2008), e Botrel, Mauricio e Daise (1999), mas similares aos de Santos et al. (2003), Molan (2004), e Mari (2003). Diferenças produtivas constatadas nos diferentes experimentos podem ocorrer em virtude de vários fatores como: ambientais, nutritivos, físicos, químicos, bióticos e o fator antrópico (BIRCH et al., 2003).

$\mathrm{O}$ acúmulo de folha foi significativa para os cultivares $(\mathrm{P}>0,05)$, sendo os maiores acúmulos nas cv. Marandú e Xaraés. Rodrigues (2004), não observou diferença entre os cultivares Marandú e Xaraés, para a acúmulo de folha e colmo, porém, observou valores muito inferiores ao relatado neste trabalho para acúmulo de folha do Xaraés e Marandú pois conduziu o trabalho no período de inverno, época de pouco crescimento forrageiro. Já Lara e Pedreira (2011), trabalhando com diferentes Brachiarias, constataram que o capim Xaraés é mais produtivo do que o Marandú, devido a suas características morfogênicas e estruturais. 
Tabela 3. Acúmulo de forragem (kg/ha), composição morfofisiológicas (\%), relação folha:colmo, densidade volumétrica de forragem $(\mathrm{kg} / \mathrm{cm} . \mathrm{ha})$ e altura do dossel forrageiro em pastos de diferentes cultivares de Brachiaria brizantha submetido a intensidades de desfolhação.

\begin{tabular}{|c|c|c|c|c|}
\hline \multirow{2}{*}{ Variáveis } & \multicolumn{3}{|c|}{ Cultivares de $B$. brizantha } & \multirow{2}{*}{$\mathrm{CV}(\%)$} \\
\hline & Marandú & MG4 & Xaraés & \\
\hline & \multicolumn{3}{|c|}{------------------------ kg/ha ----------------------- } & \\
\hline Acúmulo de forragem total & 28.067 & 22.576 & 26.805 & 25,9 \\
\hline Acúmulo de Colmo & 10.296 & 8.082 & 8.650 & 36,2 \\
\hline \multirow[t]{2}{*}{ Acúmulo de Folha } & $13.291 \mathrm{~A}$ & $9.413 \mathrm{~B}$ & $14.747 \mathrm{~A}$ & 21,6 \\
\hline & & ---0 & --- & \\
\hline Porcentagem Material Morto & $16,46 \mathrm{~B}$ & $20,92 \mathrm{~A}$ & $11,23 \mathrm{C}$ & 22,3 \\
\hline \multirow[t]{2}{*}{ Porcentagem Colmo } & $33,03 \mathrm{~A}$ & $36,14 \mathrm{~A}$ & $28,99 \mathrm{~B}$ & 12,6 \\
\hline & & $\mathrm{kg} / \mathrm{cm} \cdot \mathrm{ha}$ & ----- & \\
\hline Densidade de Forragem & $80,63 \mathrm{~A}$ & $76,06 \mathrm{~A}$ & $61,56 \mathrm{~B}$ & 19,4 \\
\hline Altura do Dossel forrageiro & $87,81 \mathrm{~B}$ & $75,88 \mathrm{C}$ & $105,19 \mathrm{~A}$ & 12,5 \\
\hline Relação folha:colmo & $1,48 \mathrm{~B}$ & $1,21 \mathrm{C}$ & $1,79 \mathrm{~A}$ & 16,9 \\
\hline
\end{tabular}

Médias seguidas por pelo menos uma mesma letra são iguais $(\mathrm{P}>0,05)$.

Fonte: Elaboração dos autores.

Verificou-se que a percentagem de material morto diferiu entre as cultivares de Brachiaria brizantha, sendo que a cv. MG4 apresentou maior percentagem deste material, seguido pelo Marandú e o Xaraés. Resultados similares foram encontrados por Flores et al. (2008), que também observaram maior proporção de material morto do capim Marandú quando comparado com o Xaraés.

Segundo Gomide e Gomide (2002), à medida que novas folhas e perfilhos jovens surgem em uma pastagem, é estabelecida entre eles uma competição crescente por luz, nutrientes e água, entre outros fatores de crescimento. Em decorrência do autosombreamento e do alongamento de colmos, intensifica-se o processo de senescência e morte das folhas mais velhas e até mesmo de perfilhos.

Muitos trabalhos demonstram que a época ideal de colheita da forragem é quando a planta atinge 95\% de interceptação luminosa, apresentando a menor produção de material senescente. Segundo Pedreira, Pedreira e Silva (2007), a Brachiaria brizantha cv. Xaraés atinge $95 \%$ de interceptação luminosa quando alcança altura média de $29,5 \mathrm{~cm}$. Trindade et al. (2007), trabalhando com o cultivar Marandú, relataram que esse cultivar atingiu 95\% de interceptação luminosa com altura média, ao longo do ano, de 24,1 cm, valores esses muito abaixo da menor altura de colheita deste trabalho.

Observou-se no presente ensaio, que a cultivar Xaraés apresentou menor percentagem de colmo quando comparado aos outros dois cultivares. Já Euclides et al. (2008), analisando três cultivares de brizantha, observaram que o Xaraés acumulou mais colmo do que o Marandú, em cortes ao nível do solo.

A densidade da forragem foi menor para o cultivar Xaraés em comparação aos demais. Os valores foram similares ao reportado na literatura para outra espécie como capim elefante cv. Guaçu (Pennisetum purpureum) de $69 \mathrm{~kg} / \mathrm{ha} . \mathrm{cm}$ de MS, e ao capim Tanzânia (Panicum maximum), com $81 \mathrm{~kg} / \mathrm{ha} . \mathrm{cm}$ de MS (PEDREIRA et al., 2005). A densidade volumétrica da forragem juntamente com a relação folha:colmo determina a taxa de 
consumo das pastagens tropicais (STOBBS, 1973; HENDRICKSEN; MINSON, 1980).

A relação folha:colmo apresentou comportamento distinto entre os cultivares, com destaque para cv. Xaraés que apresentou melhor relação, seguido pelo Marandú e a menor relação foi observado para o MG4. Bauer et al. (2011), trabalhando com diferentes cultivares de Brachiaria constataram para o capim Marandú e Xaraés, uma relação de folha:colmo de 1,93 e 2,22 respectivamente, cujos valores foram superiores ao encontrado no presente trabalho. Carard, Neres e Tonello (2008), trabalhando com níveis de adubação nitrogenada nos mesmo cultivares de Brachiaria brizantha, quando aplicado $100 \mathrm{~kg} / \mathrm{ha}$ de nitrogênio, encontraram valor similar na relação folha:colmo para os cultivares Marandú, Xaraés e MG4.

Dentre as variáveis analisadas pode-se constatar que a Brachiaria brizantha cv. Xaraés apresenta bom acúmulo de forragem, com menor porcentagem de material morto e colmo, e maior relação folha:colmo, com maior altura do dossel.

Constatou-se efeito da interação intensidade de desfolhação e cultivares de Brachiaria brizantha na composição morfológica da folha $(\mathrm{P}<0,05)$ (Tabela 4). Nos cultivares Marandú e MG4 houve variação na percentagem de folha à medida que modificouse a intensidade de desfolhação, enquanto que no cv. Xaraés não houve efeito da intensidade de desfolhação na porcentagem de folha.

Tabela 4. Composição morfológica de folha (\%) de cultivares de Brachiaria brizantha submetido a intensidades de desfolhação $(\mathrm{cm})$.

\begin{tabular}{clcc}
\hline $\begin{array}{c}\text { Intensidade de } \\
\text { desfolhação }(\mathrm{cm})\end{array}$ & Marandú & MG4 & Xaraés \\
\hline 10 & $44,53 \mathrm{~B}$ & $36,78 \mathrm{C}$ & $59,48 \mathrm{~A}$ \\
20 & $44,15 \mathrm{~B}$ & $40,78 \mathrm{~B}$ & $61,85 \mathrm{~A}$ \\
30 & $52,93 \mathrm{AB}$ & $46,65 \mathrm{~A}$ & $59,25 \mathrm{~A}$ \\
40 & $60,53 \mathrm{~A}$ & $47,53 \mathrm{~A}$ & $58,48 \mathrm{~A}$ \\
\hline
\end{tabular}

Médias seguidas por pelo menos uma mesma letra na coluna são iguais ( $P>0,05)$, Coeficiente de Variação 9,4\%.

Fonte: Elaboração dos autores.
Bauer et al. (2011), ao trabalharem com o cv. Xaraés verificaram valores similares para as intensidades de desfolhação 10 e $20 \mathrm{~cm}$ na composição morfológica da folha, no entanto, ao trabalhar com o cv. Marandú constataram resultados superiores aos encontrados neste trabalho.

Foi encontrado proporção de folha entre 44\% (10 e $20 \mathrm{~cm})$ a $60 \%(40 \mathrm{~cm})$ para o cultivar Marandú. Gerdes et al. (2000), encontraram proporção de $84 \%$ de folha para o cultivar Marandú aos 35 dias de rebrotação e Flores et al. (2008), também encontraram valores superiores para as menores intensidades de desfolhação. Rodrigues (2004), ao trabalhar com o cv. Marandú relataram maiores valores na composição das folhas do que os do presente trabalho. Pedreira e Pedreira (2007), ao trabalharem com o cv. Xaraés observaram que à medida que se aumentava a altura do pasto, aumentava a produção de massa seca decorrente do maior acúmulo de colmo, sendo que o acúmulo de matéria seca tendeu a estabilizar com $30 \mathrm{~cm}$ de altura.

Pedreira, Pedreira e Silva (2007), relataram que as plantas apresentam plasticidade fenotípica, logo ocorrem modificações no dossel para permitir maior iluminação da área foliar. Possivelmente no presente ensaio tenha ocorrido plasticidade fenotípica no pasto das cultivares de Brachiaria brizantha quando submetida a diferentes intensidades de desfolhação.

Verificou-se interação entre os cultivares de Brachiaria brizantha e intensidade de desfolhação para o acúmulo de massa seca de folha (Tabela 5). Esta interação pode ter sido devido à diminuição no acúmulo de folha, no cultivar MG4, quando houve diminuição da intensidade de desfolha. Tal fato pode ser explicado pela hábito de crescimento deste cultivar, pois quando se aumentou a altura houve tendência a decumbência e à medida que se manejou sob intensidade de cortes mais leniente (40 $\mathrm{cm}$ ) ocorreu menor produção de matéria seca na forma de folha. 
Tabela 5. Acúmulo de matéria seca de folha $(\mathrm{kg} / \mathrm{ha})$ de cultivares de Brachiaria brizantha submetido a intensidades de desfolhação.

\begin{tabular}{ccll}
\hline $\begin{array}{c}\text { Intensidade de } \\
\text { desfolhação }(\mathrm{cm})\end{array}$ & Marandú & \multicolumn{1}{c}{ MG4 } & Xaraés \\
\hline 10 & $4.680 \mathrm{~A}$ & $5.838 \mathrm{AB}$ & $2.521 \mathrm{~A}$ \\
20 & $5.960 \mathrm{~A}$ & $6.441 \mathrm{~A}$ & $2.340 \mathrm{~A}$ \\
30 & $4.758 \mathrm{~A}$ & $4.353 \mathrm{AB}$ & $4.309 \mathrm{~A}$ \\
40 & $3.520 \mathrm{~A}$ & $3.442 \mathrm{~B}$ & $4.462 \mathrm{~A}$ \\
\hline
\end{tabular}

Médias seguidas por pelo menos uma mesma letra na coluna são iguais ( $\mathrm{P}>0,05)$, Coeficiente de Variação 9,4\%.

Fonte: Elaboração dos autores.

Segundo Rodrigues (2004), a produção de folha para diferentes cultivares de Brachiaria brizantha, apresenta acúmulo retilíneo até determinado ponto, depois esse acúmulo tende a diminuir. No presente trabalho pode-se constatar essa tendência antecipada na cv. MG4 em relação a cv. Marandú e Xaraés.

Quando avaliou-se os resíduos de massa seca total, material morto, colmo e folha (Tabelas 6 e 7), constatou-se efeito significativo da intensidade de desfolhação $(\mathrm{P}<0,05)$ e efeito das cultivares de Brachiaria brizantha $(\mathrm{P}<0,05)$. Pela arquitetura do dossel forrageiro, à medida que ocorre o corte da forragem, é removido do dossel grande parte das folhas deixando como substrato o colmo, material morto e folhas remanescentes, portanto, no resíduo há tendência de grande concentração de material morto e colmo, como observado neste trabalho. Quando se diminuiu o índice de área foliar remanescente, acarretou-se em uma menor área fotossinteticamente ativa, ocorrendo maior período de tempo para alcançar o ponto ideal de colheita, resultando em perdas produtivas pelo elevado espaço de tempo entre colheitas.

Tabela 6. Resíduo de massa seca ( $\mathrm{kg} / \mathrm{ha}$ ) de cultivares de Brachiaria brizantha submetido a diferentes intensidades de desfolhação.

\begin{tabular}{ccccc}
\hline Intensidade de & \multicolumn{4}{c}{ Resíduo de MS } \\
\cline { 2 - 5 } desfolhação $(\mathrm{cm})$ & Total & Material Morto & Colmo & Folha \\
\hline 10 & $2465,7 \mathrm{C}$ & $973,5 \mathrm{~B}$ & $858,8 \mathrm{C}$ & $633,8 \mathrm{~B}$ \\
20 & $4075,8 \mathrm{BC}$ & $1623,8 \mathrm{AB}$ & $1429,4 \mathrm{BC}$ & $1022,8 \mathrm{AB}$ \\
30 & $5210,8 \mathrm{AB}$ & $2028,8 \mathrm{~A}$ & $1944,0 \mathrm{AB}$ & $1238,4 \mathrm{AB}$ \\
40 & $6286,8 \mathrm{~A}$ & $1992,7 \mathrm{~A}$ & $2664,7 \mathrm{~A}$ & $1629,5 \mathrm{~A}$ \\
\hline CV $(\%)$ & 35,9 & 42,0 & 48,4 & 52,1 \\
\hline
\end{tabular}

Médias seguidas por pelo menos uma mesma letra na coluna são iguais $(\mathrm{P}>0,05)$.

Fonte: Elaboração dos autores.

Tabela 7. Resíduo de massa seca (kg/ha) em Brachiaria brizantha cv. Marandú, MG4 e Xaraés submetida a diferentes intensidades de desfolhação.

\begin{tabular}{ccccc}
\hline Cultivares Brachiaria & \multicolumn{4}{c}{ Resíduo de MS } \\
\hline & Total & Material Morto & Colmo & Folha \\
\hline Marandú & $5202,4 \mathrm{~A}$ & $2019,2 \mathrm{~A}$ & $1967,9 \mathrm{~A}$ & $1215,5 \mathrm{AB}$ \\
MG4 & $3445,6 \mathrm{~B}$ & $1425,7 \mathrm{~A}$ & $1288,9 \mathrm{~A}$ & $731,4 \mathrm{~B}$ \\
Xaraés & $4881,3 \mathrm{~A}$ & $1519,2 \mathrm{~A}$ & $1915,8 \mathrm{~A}$ & $1446,5 \mathrm{~A}$ \\
\hline CV $(\%)$ & 35,9 & 42,0 & 48,4 & 52,1 \\
\hline
\end{tabular}

Médias seguidas por pelo menos uma mesma letra na coluna são iguais $(\mathrm{P}>0,05)$.

Fonte: Elaboração dos autores. 
Brancio et al. (2003), ao analisarem altura de resíduo pós pastejo, de três cultivares de Panicum maximum, observaram que na maior altura de resíduo houve maior percentagem de colmo, corroborando com os resultados encontrados neste trabalho. Quanto menor a intensidade de desfolhação, maior o resíduo de MS total, material morto, colmo e folha. Portanto, o aumento na altura residual influência as características morfológicas da forragem e indica que, em alguns casos, os benefícios proporcionados pela maior produção de massa forrageira podem ser devido ao maior acúmulo de material morto e colmos, resultando em forragem de valor nutritivo inferior (BIRCHAM; HODGSON, 1983; MARCELINO et al., 2006).

Alguns estudos sugerem que os colmos possam ser barreira para obtenção de pastejos mais profundos, devido à maior força requerida na sua colheita, porém, isto não tem sido confirmado (LACA e UNGAR, 1992). O aumento na concentração de colmo até $40 \mathrm{~cm}$ de resíduo, deve ser considerado em virtude da adaptação ou plasticidade fenotípica da planta a colheita, pois à medida que se aumenta a altura de colheita do dossel, ocorre competição das folhas pelo ápice do dossel em virtude da necessidade fotossintética das folhas, gerando alongamento das hastes.

À medida que o manejo de corte se eleva melhora a qualidade do material forrageiro devido ao maior percentual de participação de folhas no material forrageiro. De acordo com Marcelino et al. (2006), quanto maior a quantidade de folha melhor o valor nutritivo da forragem, e mais rápido é o tempo da rebrota. Sarmento (2007), relatou que a altura pós pastejo de $10 \mathrm{~cm}$ não foi o mais indicado como resíduo, havendo dificuldades em manejar pastagens nessa altura, e indicando $20 \mathrm{~cm}$ de resíduo como a de melhor rebrota.

Os cultivares apresentaram comportamentos distintos quando submetidos a diferentes alturas de resíduo (Tabela 7). De forma geral, o cv. MG4 apresentou os menores valores de massa seca residual total e de folhas. Este comportamento pode ser explicado pelas características estruturais deste cultivar, onde tem folhas menores e colmos mais finos do que as outras cultivares.

O capim Xaraés apresentou o maior resíduo de massa seca de folha. O colmo e o material morto apresentaram comportamentos similares entre os cultivares. A produção de material senescente está ligada a colheita da forragem acima do nível de área foliar crítico, contudo a senescência não pode ser vista apenas como perda de material, pois ela apresenta uma via eficiente de reciclagem de nutrientes para as plantas, em condições limitadas de fatores de crescimento (DA SILVA; NASCIMENTO JUNIOR; EUCLIDES, 2008).

\section{Conclusões}

Brachiaria brizantha cultivares Xaraés e Marandú apresentam maior acúmulo de folha, relação folha:colmo , maior produção de material verde no resíduo de massa seca, e menor acúmulo de material morto.

As intensidades de desfolhação de 30 e 40 cm são as mais indicadas pois apresentam menor acúmulo e percentagem de colmo e maior relação folha:colmo.

Brachiaria brizantha cultivares Marandú e Xaraés apresentam o maior resíduo total de matéria seca, e o maior resíduo de folha.

\section{Referências}

BALSALOBRE, M. A. A.; CORSI, M.; SANTOS, P. M.; VIEIRA, I.; CÁRDENAS, R. R. Composição Química e Fracionamento do Nitrogênio e dos Carboidratos do Capim-Tanzânia Irrigado sob Três Níveis de Resíduo Pós-pastejo. Revista Brasileira de Zootecnia, Viçosa, v. 32, n. 3, p. 519-528, 2003.

BAUER, M. O.; PACHECO, L. P. A.; CHICHORRO, J. F.; VASCONCELOS, L. V.; PEREIRA, D. F. C. Produção e características estruturais de cinco forrageiras do gênero brachiaria sob intensidades de cortes intermitentes. Ciência Animal Brasileira, Goiânia, v. 12, n. 1, p. 17-25, 2011. 
BIRCH, C. J.; ANDRIEU, B.; FOURNIER, C.; VOS, J.; ROOM, P. Modelling kinetics of plant canopy architecture - concepts and application. European Journal of Agronomy, Amsterdam, v. 19, n. 4, p. 519533, 2003.

BIRCHAM, J. S.; HODGSON, J. The influence of sward condition on rates of herbage growth and senescence in mixed swards under continuous stocking management. Grass and Forage Science, Oxford, v. 38, n. 4, p. 323331, 1983.

BOTREL, M. A.; MAURÍCIO, J. A.; DEISE, F. X. Avaliação de gramíneas forrageiras na região sul de Minas Gerais. Pesquisa Agropecuária Brasileira, Brasília, v. 34, n. 4, p. 683-689, 1999.

BRANCIO, P. A.; EUCLIDES, V. P. B.; NASCIMENTO JUNIOR, D.; FONSECA, D. M.; ALMEIDA, R. G.; MACEDO, M. C. M.; BARBOSA, R. A. Avaliação de Três Cultivares de Panicum maximum Jacq. sob Pastejo: Disponibilidade de Forragem, Altura do Resíduo PósPastejo e Participação de Folhas, Colmos e Material Morto. Revista Brasileira de Zootecnia, Viçosa, v. 32, n. 1, p. 55-63, 2003.

CARARD, M.; NERES, M. A.; TONELLO,C. L. Efeito de doses crescentes de nitrogênio no desenvolvimento de cultivares de brachiaria brizantha. Revista da FZVA, Uruguaiana, v. 15, n. 2, p. 135-144, 2008.

CASAGRANDE, D. R.; RUGGIERI, A. C.; JANUSCKIEWICZ, E. R.; GOMIDE, J. A.; REIS, R. A.; VALENTE, A. L. da S. Características morfogênicas e estruturais do capim-marandu manejado sob pastejo intermitente com diferentes ofertas de forragem. Revista Brasileira de Zootecnia, Viçosa, v. 39, n. 10, p. 21082115, 2010.

CASTAGNARA, D. D.; MESQUITA, E. E.; NERES, M. A.; OLIVEIRA, P. S. R.; DEMINICIS, B. B.; BAMBERG, R. Valor nutricional e características estruturais de gramíneas tropicais sob adubação nitrogenada. Archivos de Zootecnia, Cordoba, v. 60, n. 232, p. 931-942, 2011.

DA SILVA, S. C.; NASCIMENTO JUNIOR, D.; EUCLIDES, V. B. P. Pastagens: conceitos básicos, produção e manejo. Viçosa: Suprema, 2008. 115 p.

DAVIES, A. Tissue turnover in the sward. In: DAVIES, A.; BAKER, R. D.; GRANT, S. A.; LAIDLAW, A. S. (Ed.). Sward measurement handbook. 2. ed. Reading: The British Grassland Society, p. 1993. p. 183-216.

EMPRESA BRASILEIRA DE PESQUISA AGROPECUÁRIA - EMBRAPA. Centro Nacional de Pesquisa de Solos. Sistema brasileiro de classificação de solos. Brasília: Embrapa Produção de Informação, 1999. $412 \mathrm{p}$.
EUCLIDES, V. P. B.; MACEDO, M. C. M.; VALLE, C. B.; BARBOSA, R. A.; GONÇALVES, W. V. Produção de forragem e características da estrutura do dossel de cultivares de Brachiaria brizantha sob pastejo. Pesquisa Agropecuária Brasileira, Brasília, v. 43, n. 12, p. $1805-$ 1812, 2008.

FAGUNDES, J. L.; FONSECA, D. M.; GOMIDE, J. A.; NASCIMENTO JUNIOR, D.; VITOR, C. M. T.; MORAIS, R. V.; MISTURA, C.; REIS, G. C. ; MARTUSCELLO, J. A. Acúmulo de forragem em pastos de Brachiaria decumbens adubados com nitrogênio. Pesquisa Agropecuária Brasileira, Brasília, v. 40, n. 4, p. 397-403, 2005.

FAGUNDES, J. L.; FONSECA, D. M.; MORAIS, R. V.; MISTURA, C.; VITOR, C. M. T.; GOMIDE, J. A.; NASCIMENTO JUNIOR, D.; SANTOS, M. E. R.; LAMBERTUCCI, D. M. Avaliação das características estruturais do capim-braquiária em pastagens adubadas com nitrogênio nas quatro estações do ano. Revista Brasileira de Zootecnia, Viçosa, v. 35, n. 1, p. 30-37, 2006.

FLORES, R. S.; EUVLIDES, V. P. B.; ABRÃO, M. P. C.; GALBEIRO, S.; DIFANTE, G. S.; BARBOSA, R. A. Desempenho animal, produção de forragem e características estruturais dos capins marandu e xaraés submetidos a intensidades de pastejo. Revista Brasileira de Zootecnia, Viçosa, v. 37, n. 8, p. 1355-1365, 2008.

GERDES, L.; WERNER, J. C.; COLOZZA, M. T.; CARVALHO, D. D.; SCHAMMASS, E. A. Avaliação de características agronômicas e morfológicas das gramíneas forrageiras marandu, setária e tanzânia aos 35 dias de crescimento nas estações do ano. Revista Brasileira de Zootecnia, Viçosa, v. 29, n. 4, p. 947-954, 2000.

GOMIDE, C. A. M.; GOMIDE, J. A. Morfogênese de cultivares de Panicum maximum (Jacq.). Revista Brasileira de Zootecnia, Viçosa, v. 29, n. 2, p. 341-348, 2002.

HENDRICKSEN, R.; MINSON, D. J. The feed intake and grazing behaviour of cattle grazing a crop Lablab purpureus cv. Rongai. Journal of Agricultural Science, Cambridge, v. 95, n. 3, p. 547-554, 1980.

HUMPHREYS, L. R. Subtropical grass growth: II Effects of variation in leaf area index in the field. Queensland Journal of Agricultural and Animal Science, Brisbane, v. 23, n. 2, p. 358-388, 1966.

LACA, E. A.; UNGAR, E. D. Effects of sward height and bulk density on bite dimensions of cattle grazing homogeneous swards. Grass and Forage Science, Oxford, v. 47, n. 1, p. 91-100, 1992. 
LARA, M. A. S.; PEDREIRA, C. G. S. Respostas morfogênicas e estruturais de dosséis de espécies de Braquiária à intensidade de desfolhação. Pesquisa Agropecuária Brasileira, Brasília, v. 46, n. 7, p. 760-767, 2011.

LIMA, J. A.; VILELA, D. Formação e manejo de pastagem de Cynodon. In: VILELA, D.; RESENDE, J. C.; LIMA, J. (Ed.). Cynodon: forrageiras que estão revolucionando a pecuária brasileira. Juiz de Fora: Embrapa Gado de Leite, 2005. p. 59-77.

MARCELINO, K. R. A.; NASCIMENTO JUNIOR, D.; SILVA, S. C.; EUCLIDES, V. P. B.; FONSECA, D. M. Características morfogênicas e estruturais e produção de forragem do capim-marandu submetido a intensidades e freqüências de desfolhação. Revista Brasileira de Zootecnia, Viçosa, v. 35, n. 6, p. 2243-2252, 2006.

MARI, L. J. Intervalo entre cortes em capim-Marandu (Brachiaria brizantha (Hochst. ex A. Rich.) Stapf cv. Marandu): produção, valor nutritivo e perdas associadas à fermentação da silagem. 2003. Dissertação (Mestrado em Ciência Animal e Pastagens) - Escola Superior de Agricultura Luiz de Queiroz. Universidade de São Paulo, Piracicaba.

MOLAN, L. K. Estrutura do dossel, interceptação luminosa e acúmulo de forragem em pastos de CapimMarandu submetidos a alturas de pastejo por meio de lotação contínua. 2004. Dissertação (Mestrado em Ciência Animal e Pastagens) - Escola Superior de Agricultura Luiz de Queiroz, Universidade de São Paulo, Piracicaba.

PEDREIRA, B. C.; PEDREIRA, C. G. S. Fotossíntese foliar do capim-xaraés [Brachiaria brizantha (A. Rich.) Stapf. cv. Xaraés] e modelagem da assimilação potencial de dosséis sob estratégias de pastejo rotativo. Revista Brasileira de Zootecnia, Viçosa, v. 36, n. 4, p. 773-779, 2007.

PEDREIRA, B. C.; PEDREIRA, C. G. S.; SILVA, S. C. Estrutura do dossel e acúmulo de forragem de Brachiaria brizantha cultivar Xaraés em resposta a estratégias de pastejo. Pesquisa Agropecuária Brasileira, Brasília, v. 42, n. 2, p. 281-287, 2007.

PEDREIRA, C. G. S.; ROSSETO, F. A. A.; DA SILVA, S. C.; NUSSIO, L. G.; MORENO, L. S. B.; LIMA, M. L. P.; LEME, P. R. Forage yield and grazing efficiency on rotationally stocjed pastures of "Tanzania-1" guineagrass and 'Guaçu' elephantgrass. Scientia Agricola, Piracicaba, v. 62, n. 5, p. 433-439, 2005.

PINTO, J. C.; GOMIDE, J. A.; MAESTRI, M.; LOPES, N. F. Crescimento de folhas de gramíneas forrageiras tropicais, cultivadas em vasos, com duas doses de nitrogênio. Revista Brasileira de Zootecnia, Viçosa, v. 23, n. 3, p. 327-332, 1994.
RODRIGUES, D. C. Produção de forragem de cultivares de brachiaria brizantha (hochst. ex A. Rich.) Stapf. e modelagem de resposta produtiva em função de variáveis climáticas. 2004. Dissertação (Mestrado em Ciência Animal e Pastagens) - Escola Superior de Agricultura Luiz de Queiroz. Universidade de São Paulo, Piracicaba.

SANTOS, M. V. F.; DUBEUX JUNIOR, J. C. B.; SILVA, M. C.; SANTOS, S. F.; FERREIRA, R. L. C.; MELLO, A. C. L.; FARIAS, I.; FREITAS, E. V. Produtividade e Composição química de gramíneas tropicais na zona da mata de Pernambuco. Revista Brasileira de Zootecnia, Viçosa, v. 32, n. 4, p. 821-827, 2003.

SARMENTO, D. O. L. Produção, composição morfológica e valor nutritivo da forragem em pastos de Brachiaria brizantha (Hochst ex A. Rich) Stapf. cv Marandu submetidos a estratégias de pastejo rotativo por bovinos de corte. 2007. Tese (Doutorado em Ciência Animal e Pastagens) - Escola Superior de Agricultura Luiz de Queiroz. Universidade de São Paulo, Piracicaba.

STATISTICAL ANALYSIS SYSTEM INSTITUTE SAS. 9.0. Cary, SAS Institute Incorporated, NC, USA, 2002.

SECRETARIA DE ESTADO DE SERGIPE DO MEIO AMBIENTE E DOS RECURSOS HÍDRICOS - SEMARH. 2012. Disponível em: <http://www. semarh.se.gov.br/meteorologia/modules/tinyd0/index. php?id=50/>. Acesso em: 12 jun. 2012.

SILVA, H. A. S.; KOEHLER, H. S.; MARAES, A.; GUIMARÂES, V. A.; HACK, E.; CARVALHO, P. C. F. Análise da viabilidade econômica da produção de leite a pasto e com suplementos na região dos Campos Gerais - Paraná. Ciência Rural, Santa Maria, v. 38, n. 2, p. 445450, 2008.

SILVA, J. B.; REIS, S. T.; ROCHA JÚNIOR, V. R.; SALES, E. C. J.; MOTA, V. J. G.; JAYME, D. G.; SOUZA, V. M.. Características fermentativas da silagem do capim Marandu manejado em diferentes alturas de dossel. Revista Brasileira de Saúde e Produção Animal, Salvador, v. 12, n. 2, p. 329-339, 2011.

STOBBS, T. H. The effect of plant structure on the intake of tropical pastures. I. Variation in bite size of grazing cattle. Australian Journal of Agricultural Research, Collingwood, v. 24, n. 6, p. 809-818, 1973.

TEIXEIRA, G. A.; OLIVEIRA, M. E.; SOUSA JÚNIOR, A.; VERAS, A. S. C.; BATISTA, A. M. V.; ALVES, K. S.; RIBEIRO, V. L.; SILVA, M. J. M. S.; MEDEIROS, G. R.; VASCONCELOS, R. M. J.; ARAÚJO, A. O.; MIRANDA, S. B. Desempenho de ovinos sem raça definida em pastagens dos capins brizantha, tifton- 85 e tanzânia. In: REUNIÃO DA SOCIEDADE BRASILEIRA 
DE ZOOTECNIA, 40., 2003. Santa Maria. Anais... Santa Maria: SBZ, 2003.

TRINDADE, J. K.; SILVA, S. C.; SOUZA JUNIOR, S. J.; GIACOMINI, A. A.; ZEFERINO, C. V.; GUARDA,V. D. A.; CARVALHO, P. C. F. Composição morfológica da forragem consumida por bovinos de corte durante o rebaixamento do capim-marandu submetido a estratégias de pastejo rotativo. Pesquisa Agropecuária Brasileira, Brasília, v. 42, n. 6, p. 883-890, 2007.
VALLE, C. B.; JANK, L.; RESENDE, R. M. S.; BONATO, A. N. V. Lançamentos de cultivares forrageiras: o processo e seus resultados - cvs. Massai, Pojuca, Campo Grande, Xaraés. In: NÚCLEO DE ESTUDOS EM FORRAGICULTURA, 4., 2003, Lavras. Proceedings... Lavras: Universidade Federal de Lavras, 2003. p. 179-225. 
